\title{
Application of the TDABC Model in the Logistics Process Using Different Capacity Cost Rates
}

\author{
Paulo Afonso(iD, Alex Santana ii \\ University of Minho (Portugal) \\ psafonso@,dps.uminho.pt, afbsantana@,hotmail.com
}

Received: July 2016

Accepted: October 2016

\section{Abstract:}

Purpose: The understanding of logistics process in terms of costs and profitability is a complex task and there is a need of more research and applied work on these issues. In this research project, the concepts underlying Time-Driven Activity Based Costing (TDABC) have been used in the context of logistics costs.

Design/methodology/approach: A Distribution Centre of wood and carpentry related materials has been studied. A multidisciplinary team has been composed to support the project including the researchers and three employees of the company responsible for accounting, logistics and warehousing. The design and implementation of the costing model asked for a deep understanding of the different tasks and processes that should be considered. Accordingly, a TDABC model for the logistics function was developed.

Findings: The cost model presented here is supported on a series of time equations designed for the logistics function which allow the analysis and discussion of costs and profitability of different cost objects namely, products, clients, distribution channels, processes and activities. The cost of unused capacity and the effectiveness of logistics processes are also highlighted in this model.

Research limitations/implications: In a case study, results and implications cannot be directly or immediately generalized. Nevertheless, the proposed time equations and cost model can be 
easily adapted to explain other types of logistics functions and it gives the foundations or other TDABC models with more than one capacity cost rate.

Practical implications: The TDABC model developed in this case study can be used in similar cases and as a basis for the analysis of logistics costs in other logistics processes. Furthermore, managers can rely on the proposed approach to analyze products' profitability and logistics cost structure.

Originality/value: In this case, different capacity cost rates were computed in order to reflect appropriately the logistics function which was presented in two different processes: internal logistics and distribution. These processes have specific resources allocated and should be measured differently. This is in line with Kaplan and Anderson $(2004,2007)$ who have suggested a more complex TDABC model with more than one capacity cost rate for these situations.

Keywords: logistics costs, Time-Driven Activity Based Costing (TDABC), capacity costs, capacity cost rate, case study

\section{Introduction}

In many companies the costs vary considerably according to the diversity of the product and/or the complexity of operations, therefore there is a need for more elaborate and dynamic costing systems (Gunasekaran \& Sarhadi, 1998). Such necessity is due to the fact that the information provided by traditional costing systems is not complete or sufficiently credible for managers take good decisions for both strategic and operational purposes. In this sense, Johnson and Kaplan (1993) report that the onset of strategic cost management is due to the fact that the information provided by traditional costing systems is not good enough. Although some traditional costing systems provide detailed reports they may not be effective and do not reflect the activities and processes that define the organization.

Traditional costing systems are not able to determine accurately the cost of different cost objects once based mainly on volume measures for costing allocations. Furthermore, traditional costing systems are not enough flexible and cannot be easily adapted to changes in the market demand (Baykasoglu \& Kaplanoglu, 2008; Themido, Arantes, Fernandes \& Guedes, 2000). Modern costing systems should be dynamic and flexible, allowing the computation of different types of cost objects namely, products, activities, distribution channels, clients, etc. taking into account all diversity and complexity that characterize modern production and business processes. 
Furthermore, in companies with a major logistics function or in which supply chain management activities are critical factors of the production and business processes, logistics costs deserve particular attention and should be charged conveniently to relevant cost objects. In these cases, logistics costs are a competitiveness factor and should be properly analyzed. Such companies should focus their attention on specific logistic activities as order processing, internal materials handling, storage cost, costs associated with vehicles, among others. Nevertheless, the measurement and allocation of logistics costs is complex. This is due to the lack of information on the indirect costs, the high complexity of logistics activity and the fact that most companies consider logistics costs as merely indirect and period costs (Goldsby \& Closs, 2000). However, these costs affect very differently the various relevant cost objects, i.e. distribution channels, routes, distribution centers, orders and specific customers and ultimately the cost of each product sold. According to Manunen (2000) in general, logistics costs depend on the type of the business and the company's structure, among other aspects.

In this context, the data provided by activity based costing systems may improve managers' knowledge of logistics and enable companies to optimize logistics operations, eliminate or relocate activities and resources, increase competitiveness and reduce costs. It can be found some references in the literature linking Activity Based Costing (ABC) systems and logistics costs (e.g. Baykasoglu \& Kaplanoglu, 2008; Dalci, Tanis \& Kosan, 2010; Everaert, Bruggeman, Sarens, Anderson \& Levant, 2008; Fernie, Freathy \& Tan, 2001; Goldsby \& Closs, 2000; Pernot, Roodhooft \& Van den Abbeele, 2007). But there is a need for more and better applications of costing systems in the logistics context. Furthermore, these last years, ABC models evolved from the initial ABC approach to the recent Time-Driven ABC (TDABC) (Kaplan \& Anderson, 2004).

In this project, we developed and implemented a TDABC model for the logistics function in particular company. This approach allowed to gather information from the real environment where the research problem can be contextualized, analyzing in detail the data in order to understand patterns and behavior and, finally, present conclusions that explain the phenomenon studied (Yin, 2014).

A Distribution Centre of wood and materials for carpentry has been studied and the results of the application of the TDABC model in the logistics function are presented.

Such type of company considers a set of logistics constraints that are relevant cost drivers namely, storage, load capacity (in terms of weight or volume) distribution window, discharge restrictions and customer priorities (e.g. urgent delivery). The management of the costs of the logistics function is critical to the business success of this type of company for the reasons described above, and also because it contributes for a better decision-making (e.g. route planning, loading, margins and pricing strategies). 
The remainder of the paper is organized as follows. Next section presents the main concepts and principles that support TDABC. The third section explains the methodology and the case study. Subsequently, the proposed model and the results of its application are presented and discussed. Finally, the concluding remarks are outlined.

\section{Time-Driven Activity Based Costing}

Cost management has been evolving from a traditional approach mainly focused on overhead allocation and product costing to a most complete analysis of organization's cost structure, value analysis and strategic cost management. Activity Based Costing (ABC) systems and more recently Time-Driven Activity Based Costing (TDABC) systems are particularly important in this context. Activity Based Costing is a costing method that measures costs and the performance of activities and cost objects. It is based on the three following assumptions: products require activities; activities consume resources and resources cost money. It emphasizes that activities consume resources and, that products consume activities. $\mathrm{ABCM}$ models evolved from the initial $\mathrm{ABC}$ to the more recent TDABC which is supported on time equations.

Thus, traditional costing methods have been substituted by activity based cost management (ABCM) approaches which rely on the full (absorption) costing principle. Nevertheless, these approaches explain and reflect much better the production flow and the production conditions and restrictions through the use of more cost centres and better cost drivers (Cooper \& Kaplan, 1988).

$\mathrm{ABC}$ systems offer a more accurate and detailed study of the processes and activities behind cost objects (typically, products and services but also orders, clients, etc.) than traditional costing systems. This happens mainly because the use of more and more appropriate cost drivers which explain better the causal relationship between resources and activities, firstly, and between activities and cost objects, subsequently.

Nevertheless, ABC systems are not free of criticisms and limitations. Kaplan and Anderson (2004) recognized the limitations of the $\mathrm{ABC}$ and agreed with some of them namely: (i) the high investment to implement the method, (ii) the complexity to keep it in the company and (iii) the difficulty for modifying it where necessary. For Stouthuysen, Swiggers, Reheul and Roodhooft (2010) the ABC system is often viewed as a system of high cost of development, relatively complex and difficult to be modified or adapted which often leads to be non-used. Ness and Cucuzza (1995) state that many companies have adopted and explored the feasibility of $\mathrm{ABC}$, however, they found that less than $10 \%$ have used it to 
support the management of its operations, and that the other $90 \%$ have stagnated or dropped their use in the enterprise, due to the difficulty of training and employee engagement on the potential of the tool.

Accordingly, Kaplan and Anderson (2004, 2007) develop the TDABC, a more "transparent methodology, scalable, easy to implement and update", which allows managers to obtain important information about costs and profitability, quickly and inexpensively. TDABC is presented as a simpler and more affordable system than the traditional $\mathrm{ABC}$ approach, simplifying the costing process and eliminating the need of surveys and interviews as required in an ABC (Kaplan \& Anderson, 2007). TDABC was created to address the difficulties faced by the implementation of $\mathrm{ABC}$ models and uses duration drivers instead of transaction drivers which can be easily revised when conditions change (Everaert \& Bruggeman, 2007; Hedman, Sundkvist, Almström \& Kinnander, 2013; Hoozée \& Bruggeman, 2010).

A time-driven costing process automatically reveals any differences between the total time needed to carry out all of the activities performed by a department and the total amount of time the department's employees have available. This makes time-driven $\mathrm{ABC}$ a more rigorous methodology for $\mathrm{ABC}$ programs in which better capacity management is an objective (Barrett, 2005).

There are several case studies on the implementation of the TDABC, where it is possible to observe its advantages, namely that it is a model of easy design and integration with software (Pernot et al., 2007). Through TDABC it is possible to study the effectiveness of the processes in terms of available capacity versus used capacity. Thus, among other advantages, TDABC permits to assess the added value that determines the existence of each activity, simulate the use of resources, etc. But also limitations were noted in some case studies in which, for example, there was the fact that it can be required a huge amount of data for estimating time equations (Bryon, Everaert, Lauwers \& Van Meense, 2008; Varila, Seppänen \& Suomala, 2007).

TDABC is supported on two key parameters, the cost per time unit of capacity and the time required to complete an activity - time is typically considered the measure of the capacity (Kaplan \& Anderson, 2007). It is a model that assigns resource costs directly to cost objects. Thus, it first calculates the costs of all resources (equipment, personnel, etc.) and, subsequently, divides them by the capacity, which is the time for the execution of the work, effectively used. Secondly, the model distributes the resource costs using the capacity cost rate and the conditions and resource requirements for each cost object (Everaert, Bruggeman \& De Creus, 2008; Sarokolaei, Saviz, Moradloo \& Dahaj, 2013).

A TDABC system is presented in the form of time equations which reflect the costs of different cost objects taking into account the particularities of consumption of each activity by each particular product, assuming a standard time of execution of the activity plus an incremental time to perform additional 
activities. Thus, it is a model that assigns resource costs directly to cost objects (Homburg, 2005; Kaplan \& Anderson, 2007; Kont \& Jantson, 2011).

According to Huang, Chen, Chiu and Chen (2014), TDABC uses standard data as a starting point as well as a basis for the calculations, which reduces the amount of data to be collected (Gervais, Levant \& Ducrocq, 2010). Second, ABC ignores resource constraints.

Mathematically, the TDABC can be explained as follows, using time equations (Bruggeman, Everaert, Anderson \& Levant, 2005). In a time equation, the time consumed by the event in the activity can be expressed as a function of different characteristics called time drivers. The general time equation needed by the event $\mathrm{E}$ of the activity A with $\mathrm{p}$ of possibility is given by:

$$
t_{E, A}=\beta_{0}+\beta_{1} * X_{1}+\beta_{2} * X_{2}+\beta_{3} * X_{3}+\beta_{P} * X_{P}
$$

$T_{E, A}-$ Time required for executing the event $E$ in terms of activity $A$

$\beta_{0}-$ constant amount of time for activity $A$

$\beta_{1}-$ time consumed per unit of time driver 1

$X_{1}$ - time driver 1

$X_{p}$ - time driver $p$

$p$ - number of drivers needed to run the activity $A$

Converting an $\mathrm{ABC}$ model in a TDABC can be a relatively simple process. The relationships between resource cost pools, activities and cost objects identified in an $\mathrm{ABC}$ model can be adopted in a TDABC based model via 'resource groups' (e.g. support staff, facilities, administration) and using multiple time-based drivers to allocate costs to cost objects or eventually, using a single time-based driver if there are complexities in the collection of the data. 


\section{Case Study and Research Method}

The studied company was a Distribution Centre (DC) of wood and carpentry related materials where the TDABC model for the logistics function was designed and applied. The company is a solid reference in the Portuguese market with a turnover about 25 million euros, a portfolio with more than 8,000 products and over than 5,000 customers. This company operates in a very competitive environment which results in margins significantly reduced.

The activity of the company breaks down in two business units, one dedicated to providing cutting services as, selvedging, drilling and milling wood and its derivatives (e.g. kits for kitchens, kitchen doors) and another one specialized in the commercialization of decks, floating laminate and wood, vinyl and sustainable solutions in bamboo and composite materials, etc. This company is also a commercial agent for the domestic market of several international brands.

It is important to notice that the company's sales have a clear seasonality in the months of June and July when the volume of sales is high in contrast to the months of August and December. The distribution of these products is mainly ensured by the company's fleet that transports daily (5 days per week) the products to the clients from each distribution center.

The company is comprised by three distribution centers (DC) which are managed, mostly autonomously. All DC have similarities but also different. The DC of Braga and Leiria are warehouses focused on the commercialization of wood materials and components. On the other hand, the DC located at Póvoa de Varzim is used for the storage and distribution of wood representing a lower volume of sales.

This research project focuses on the company's larger DC, located at Braga, which represents more than half of total sales. Every day, on average, this DC supplies 50 customers and makes 74 orders. Note that each client may perform more than one order, and each order can include several products. Thus, the optimization of loads and routes is particularly important in this context. The DC of Leiria amounts to 36 orders corresponding to 28 customers. The DC of Póvoa de Varzim is responsible for 24 orders on average requested by 18 clients.

Customers are mainly large woodworks who transform wood plates and boards in final products for the end consumer and also for resellers, retailers, among others.

The company's fleet ensures the distribution for all cases, but typically, a customer who buys directly in the DC carries on the materials in his/her own vehicle. It is important to mention that not all customers have good discharge requirements, including small carpentry that do not have trucks to help to transport from the truck to the warehouse as well as good access for the entry and exit of the trucks. 
The main suppliers of wood derivative are located at the Iberian Peninsula whereby the material is transported by truck, having a lead time of 1 to 2 weeks on average, while in the case of hardwood materials is essentially transported by ship, having on average a lead time of 6 weeks.

A case study approach was been followed to design the TDABC costing model explained and discussed in the next section. In this case study we proceeded to collect the relevant data through document analysis, historical analysis concerning cost information, the analysis of internal documents, records and files provided by the company, direct observation, and finally, questionnaires applied to the workers.

For Yin $(1994,2014)$ a case study is a research method for an empirical research on a particular topic in the light of its real environment, particularly useful when the boundaries between the research topic under study and its context are unclear or relatively unknown. It asks for the use of several sources of empirical evidence which allow the triangulation of the data. According to Yin (1994, 2014), case studies can be divided into descriptive, exploratory and causal. In the first case, the aim is to describe the behavior of certain systems, techniques or procedures that occur in practice. In the second case it is used when the goal is to explore reasons or practices to prove the falsity or not of a particular theory and how this can be changed. In the third case, the aim is to find a relation between variables of cause and effect.

A research methodology outlines how the research must be conducted and gives the guidelines for strategy that must be followed in order to reach the intended goals. To make an inquiry about a particular topic it is necessary to go through several phases that are inextricably linked, with each phase being covered more than once if necessary Saunders, Philip and Thornhill (2009) particularly, the design of the research, the collection and the analysis of the data.

In this case, the analysis and data collection were performed at two different moments. Initially, through the analysis of internal documents of the company, then the data collection was conducted through direct and participatory observation, questioning workers about the tasks that they perform. It was also made a photographic record to document and analyze the operations. The collection of this data made in loco took about three months.

The data analyzed refer to a half year of the company's activity and it is representative of its business cycle. In this period the months of higher and lower sales volume are both represented. June and July correspond to the months of highest volume since August and December represent the months of lower sales volume.

In the beginning of this research it was carried out a questionnaire presented to employees which was important to have an overview of the company's production processes. The more relevant activities for 
the purpose of this research were storage and distribution which include material handling, customer service, picking and shipping operations.

A multidisciplinary team has been composed to support the project including the researchers and three employees of the company: the responsible for accounting, the logistics director and the responsible for the warehouse. The accounting officer has a good knowledge of the costing system used in the company as well as its limitations. The logistics director knows the entire logistics process from the entry of an order through to the delivery to the customer. The head of the warehouse is familiar with all logistics operations.

During the first stage of the field work, they were determined which activities should be included in the costing system, taking into account parameters such as the duration of each activity, the resources consumed, among others. In some cases the activities were grouped into macro activities.

The determination of activities presented resulted from the observation "in loco" of workers in their jobs for several moments, these have been questioned about how and why perform the different activities.

The conducted study focused on the logistics business processes, in particular, planning loads, picking and distribution to customers. As it was already explained, before starting the application of the TDABC model in the company it was necessary to study each of the areas mentioned for several weeks at different times in order to acquire a deep understanding of the various tasks/processes that would be relevant for the cost model. The objective was to identify and compute the logistics costs, which should take into account order planning, picking, packaging and distribution of the material among other activities. These activities demand the typical resources involved in logistics processes namely, workforce, warehouse, fuel, energy, depreciation of vehicles, forklifts and communication expenses, among others.

Thus, this study was based on the company's business environment and aimed to describe and analyze in detail the company's resources, activities and cost objects that make up the logistics process in order to develop an adequate TDABC model.

\section{Results and Discussion}

After an in-depth study of the activities in the Distribution Centre, it was decided to explain the logistics function in terms of two main processes: internal logistics and distribution. Each one has specific resources and can be expressed in different output measures. Furthermore, distribution activities are developed using two different types of vehicles (four trucks of 3.6 ton and one of 11 ton) and it was also decided to present the distribution process in two sub-processes. 
The design of a TDABC model asks for two main steps: 1) to calculate the capacity cost rate(s) (see Equation 2) and 2) to design the time equations which reflect the demand for resource capacity. After these steps, we will be able to make different analysis of costs and profitability.

The practical capacity of the distribution sub-processes was obtained from the average $\mathrm{km} /$ day that the different vehicles are used to make. Furthermore, the practical capacity of internal logistics was calculated in minutes and it is approximately 5000.000 minutes for the period under study $(147$ days $(7$ months $) \times 8$ hours (day) $\times 9$ employees $\times 0.775$ (efficiency rate) $\times 60$ minutes). This information was collected directly from the company's ERP system.

$$
\text { Capacity Cost Rate }=\frac{\text { Cost of Capacity Supplied }}{\text { Practical Capacity of Resources Supplied }}
$$

Table 1 explains the computation of the three relevant capacity cost rates for the logistics function.

\begin{tabular}{|c|r|c|r|c|}
\cline { 2 - 5 } \multicolumn{1}{c|}{} & \multicolumn{1}{c|}{ Resources } & Drivers & Practical Capacity & Capacity Cost Rate \\
\hline Internal Logistics & 220,448 & Minutes & 500,000 & $0.44 € / \mathrm{min}$ \\
\hline Distribution 1 & 55,089 & Kms & 95,000 & $0.58 € / \mathrm{Kms}$ \\
\hline Distribution 2 & 36,229 & Kms & 16,500 & $2.20 € / \mathrm{Kms}$ \\
\hline
\end{tabular}

Table 1. Computation of Capacity Cost Rates

Step two asks for the design of time equations. In this case, one time equation measures the capacity in minutes ( $T_{1}$ : Internal Logistics) but the other two use $\mathrm{kms}$ as the cost driver ( $T_{2}$ and $T_{3}$, respectively, Distribution by the 3.6 ton vehicles and Distribution by the 11 ton vehicle).

The study of the internal logistics has showed that the time consumed in the different activities which compose this process such as picking and others is dependent on product category and five different categories have been considered (Components, Kitchen Products, Panels, Pavements and finally a category of Others) and the estimated amount of minutes necessary by $\mathrm{kg}$ of each of these products have been estimated. Time Equation 1 for internal logistics is presented below; firstly, generically and secondly, $\beta_{s}$ are substituted by their values (Equations 3 to 6).

$$
T_{1}=\Sigma_{i=1}^{5} \beta_{i} X \text { ProductCat }_{i}(K g)
$$

ProductCat $_{i=1 . .5}$ Components, KitchenProd, Panels, Pavements, Others

$$
\begin{gathered}
T_{1}=\beta_{1}[\text { Components }(K g)]+\beta_{2}[\text { KitchenProd }(K g)]+\beta_{3}[\text { Panels }(K g)] \\
+\beta_{4}[\text { Pavements }(K g)]+\beta_{5}[\text { Others }(K g)]
\end{gathered}
$$




$$
\begin{aligned}
& T_{1}=1 \min [\text { Components }(\mathrm{Kg})]+0,5 \mathrm{~min}[\text { KitchenProd }(\mathrm{Kg})] \\
& \quad+0,10 \mathrm{~min}[\text { Panels }(\mathrm{Kg})]+0,40 \mathrm{~min}[\text { Pavements }(\mathrm{Kg})] \\
& +1,5 \mathrm{~min}[\text { Others }(\mathrm{Kg})]
\end{aligned}
$$

In terms of distribution, costs depend on the number of freights which are organized by radius (Radius less than $50 \mathrm{kms}$, between 51-100 kms, 101-200 kms, 201-400 kms and more than $400 \mathrm{kms})$. The average number of $\mathrm{kms}$ of each freight within the different radius has been estimated for the two sub-processes ( $T_{2}$ and $T_{3}$ : Distribution by the 3.6 ton vehicles and Distribution by the 11 ton vehicle, respectively). Time Equations 2 and 3 are presented in general terms and show the average kms of each freight by radius.

The equations for the sub-process Distribution made by vehicles of 3.6 ton are presented below. The study of the freights made by the different vehicles and $\mathrm{kms}$ traveled turn possible to establish the average value of each freight by radius in kms; respectively: $30 \mathrm{kms}, 80 \mathrm{kms}, 150 \mathrm{kms}, 275 \mathrm{kms}$ and $450 \mathrm{kms}$ (Equations 7 to 10$)$.

$$
\begin{aligned}
& T_{2}=\Sigma_{i=6}^{10} \beta_{i} \text { X FreightsRadius }{ }_{i} \\
& \text { Radius }_{i=6 \ldots 10}=\text { Radius }(0-50 \mathrm{kms}), \text { Radius }(51-100 \mathrm{kms}), \text { Radius }(101-200 \mathrm{kms}) \text {, } \\
& \text { Radius }(201-400 \mathrm{kms}) \text {, Radius }(>400 \mathrm{kms}) \\
& T_{2}=\beta_{6}\left[\text { FreightsRadius }_{6}\right]+\beta_{7}\left[\text { FreightsRadius }_{7}\right]+\beta_{8}\left[\text { FreightsRadius }_{8}\right] \\
& +\beta_{9}\left[\text { FreightsRadius }_{9}\right]+\aleph_{10}\left[\text { FreightsRadius }_{10}\right] \\
& T_{2}=30 \mathrm{kms}\left[\text { FreightsRadius }_{6}\right]+80 \mathrm{kms}\left[\text { FreightsRadius }_{7}\right] \\
& \left.+150 \mathrm{kms} \text { [ FreightsRadius }{ }_{8}\right]+275 \mathrm{kms}_{\text {[ FreightsRadius }} \text { ] } \\
& +450 \mathrm{kms} \text { [ FreightsRadius }{ }_{10} \text { ] }
\end{aligned}
$$

The equations for the sub-process Distribution made by the vehicle of 11 ton are presented below. The average value of each freight of the 11 ton vehicle by radius is, respectively: $35 \mathrm{kms}, 70 \mathrm{kms}, 140 \mathrm{kms}$ and $275 \mathrm{kms}$ (Equations 11 to 14$)$.

$$
T_{3}=\Sigma_{i=11}^{14} \beta_{i} X \text { FreightsRadius }{ }_{i}
$$

$$
\begin{aligned}
& \text { Radius }_{i=11 \ldots 14}=\text { Radius }(0-50 \mathrm{kms}), \text { Radius }(51-100 \mathrm{kms}), \text { Radius }(101-200 \mathrm{kms}) \text {, } \\
& \text { Radius }(201-400 \mathrm{kms}) \\
& T_{3}=\beta_{11}\left[\text { FreightsRadius }_{11}\right]+\beta_{12}\left[\text { FreightsRadius }_{12}\right] \\
& +\beta_{13}\left[\text { FreightsRadius }_{13}\right]+\aleph_{14}\left[\text { FreightsRadius }_{14}\right] \\
& T_{3}=35 \mathrm{kms}\left[\text { FreightsRadius }_{11}\right]+70 \mathrm{kms}\left[\text { FreightsRadius }_{12}\right] \\
& +140 \mathrm{kms} \text { [FreightsRadius }{ }_{13} \text { ] } \\
& \left.+275 \mathrm{kms} \text { [ FreightsRadius }{ }_{14}\right]
\end{aligned}
$$


These time equations can be used to estimate the consumption of resources in the logistics processes and using the capacity cost rate we are able to determine the cost of a specific cost object (e.g. order, freight or client). Tables 2 and 3 explain how the TDABC model that has been developed was used to compute the cost of unused capacity. Values are presented in aggregated for the three defined time equations.

\begin{tabular}{|l|r|r|r|r|r|}
\cline { 2 - 6 } \multicolumn{1}{c|}{} & \multicolumn{1}{c|}{\begin{tabular}{c} 
ProdCat \\
\multicolumn{1}{c|}{}
\end{tabular}} & \multicolumn{1}{c|}{$\begin{array}{c}\text { ProdCat } \\
\text { Radius }\end{array}$} & $\begin{array}{c}\text { ProdCat } \\
\text { Radius }\end{array}$ & $\begin{array}{c}\text { ProdCat }_{4} \\
\text { Radius }_{3}\end{array}$ & $\begin{array}{c}\text { ProdCat }_{5} \\
\text { Radius }_{5}\end{array}$ \\
\hline Internal Logistics - min & 18,963 & 71,522 & $3,096,142$ & 49,117 & 30,176 \\
\hline Distribution 1 - km & 182 & 168 & 224 & 42 & 7 \\
\hline Distribution 2 - km & 28 & 49 & 28 & 21 & 0 \\
\hline
\end{tabular}

Table 2. Information for Time Equations

Table 2 presents the information regarding the time taken in the internal logistics (in minutes) and the kilometers covered by the two different types of vehicles (trucks of 3.6 ton and the one of 11 ton) for delivering the different categories of products.

\begin{tabular}{|l|r|r|r|r|c|c|}
\cline { 2 - 7 } \multicolumn{1}{c|}{} & \multicolumn{1}{c|}{ Total } & Capacity Cost Rates & Practical Capacity & Unused Capacity & Cost & $\%$ \\
\hline Internal Logistics & $429,249 \mathrm{~min}$ & 0.44 & 500,000 & 70,751 & 31,130 & $14 \%$ \\
\hline Distribution 1 & $67,200 \mathrm{~km}$ & 0.58 & 95,000 & 27,800 & 16,124 & $29 \%$ \\
\hline Distribution 2 & $14,105 \mathrm{~km}$ & 2.2 & 16,500 & 2,395 & 5,270 & $15 \%$ \\
\hline
\end{tabular}

Table 3. Computation of Unused Capacity

These results highlight the cost of unused capacity and in which logistic processes and sub-processes that problem is more significant (Table 3). The capacity unused or idle capacity is obtained by the difference between the resources allocated to products effectively produced and the total available capacity. The model can be easily updated and several simulations can be made.

Finally, Tables 4, 5 and 6 present an analysis of the gross margins by product category (respectively, in aggregate, for the product categories 1 and 2, and product categories 3 to 5 . 


\begin{tabular}{|l|r|r|}
\cline { 2 - 3 } \multicolumn{1}{c|}{} & \multicolumn{1}{c|}{ Costs } & $\%$ \\
\hline Internal Logistics & 189,254 & 8 \\
\hline Distribution 1 & 38,968 & 2 \\
\hline Distribution 2 & 30,970 & 1 \\
\hline Direct Costs & $1,881,734$ & 81 \\
\hline Sales & $2,333,189$ & 100 \\
\hline Margins & 192,262 & 8 \\
\hline Margins $(\%)$ & & \\
\hline
\end{tabular}

Table 4. Analysis of Margins I

\begin{tabular}{|l|r|r|}
\cline { 2 - 3 } \multicolumn{1}{c|}{} & ProdCat $_{1}$ & ProdCat $_{2}$ \\
\hline Internal Logistics & 8,361 & 15,767 \\
\hline Distribution 1 & 3,166 & 7,794 \\
\hline Distribution 2 & 2,152 & 7,531 \\
\hline Direct Costs & 70,788 & 112,862 \\
\hline Sales & 101,125 & 161,231 \\
\hline Margins & 16,652 & 17,277 \\
\hline Margins $(\%)$ & 16 & 11 \\
\hline
\end{tabular}

Table 5. Analysis of Margins II

\begin{tabular}{|l|r|r|r|}
\cline { 2 - 4 } \multicolumn{1}{c|}{} & \multicolumn{1}{c|}{ ProdCat $_{3}$} & \multicolumn{1}{c|}{ ProdCat $_{4}$} & \multicolumn{1}{c|}{ ProdCat $_{5}$} \\
\hline Internal Logistics & 136,508 & 8,662 & 19,957 \\
\hline Distribution 1 & 19,484 & 6,698 & 1,827 \\
\hline Distribution 2 & 8,607 & 12,680 & 0 \\
\hline Direct Costs & $1,603,895$ & 60,347 & 33,842 \\
\hline Sales & $1,955,969$ & 73,594 & 41,270 \\
\hline Margins & 187,475 & $-14,793$ & $-14,355$ \\
\hline Margins (\%) & 10 & -20 & -35 \\
\hline
\end{tabular}

Table 6. Analysis of Margins III

These results show that two product categories are not profitable. Thus, several measures can be proposed namely, to increase the prices of these products, reduction of internal these products or reduction of the related distribution costs. Time equations are logistics costs related to particularly useful to study and simulate these and different alternatives. In fact, this TDABC model can be used to design and evaluate the impact of these and other strategies. 
Thus, this model highlights the need of cost objects aligned with the activities of logistics and distribution. Accordingly, some metrics can be proposed to manage these costs and support decision making namely pricing and margins strategy. For example, cost per product segment, cost per distance of distribution, cost per kilogram sold, cost per kilometre travelled, among others.

If the company does not known which costs support for distributing to the different clients and to the different locations, it may incur in losses or some clients may be subsidizing the others. In these cases, profitable clients are paying more than necessary and the company can lost them in the mid or long term. If this happens, the amount of not profitable clients will increase and the average margin and global profit will decrease constantly even if the dales and market share increase.

The cost model proposed here can be a valuable tool to provide more complete and accurate information about the logistics costs and real profitability of the different clients and the margins of the different categories of products and distribution zones.

Furthermore, it provides information about the areas that potentially should not be supplied and, in particular, which margins should be applied. Finally, the study of logistics costs can provide information for restructuring the most costly activities in order to optimize the logistics process of the company.

\section{Conclusions}

In this research project a Time-Driven Activity Based Costing (TDABC) for the logistics process using different capacity cost rates has been designed and applied in a Distribution Centre of wood and carpentry related materials. This case is particularly interesting because it shows that in these cases it is necessary to compute different capacity cost rates in order to reflect appropriately the logistics function, presented in this case in two different processes: internal logistics and distribution.

These processes have specific resources allocated and can be measured through different outputs. In these cases, Kaplan \& Anderson (2004, 2007) suggest a more complex TDABC model with more than one capacity cost rate. The understanding of logistics processes in terms of costs and profitability asks for such specific cost models. This paper presents the time equations designed for the case, the cost of the relevant cost objects, the cost of unused capacity and an analysis of the margins. The TDABC model developed in this case study can be used as a basis for the design of more robust logistics cost models and it can be applied in other similar cases. 


\section{Acknowledgments}

This work has been support by COMPETE: POCI-01-0145-FEDER-007043 and FCT - Fundação para a Ciência e Tecnologia within the Project Scope: UID/CEC/00319/2013; Programa Ciência sem Fronteiras and Coordenação de Aperfeiçoamento de Pessoal de Nível Superior (CAPES) Proc. n BEX 1066/13-7.

\section{References}

Barrett, R. (2005). Time-driven costing: the bottom line on the new ABC. Business Performance Management, 35-39.

Baykasoglu, A., \& Kaplanoglu, V. (2008). Application of activity-based costing to a land transportation company: A case study. International Journal of Production Economics, 116, 308-324. https://doi.org/10.1016/j.ijpe.2008.08.049

Bruggeman, W., Everaert, P., Anderson, S.R., \& Levant, Y. (2005). Modeling Logistics Costs using TimeDriven ABC: A Case in a Distribution Company. Conceptual Paper and Case Study.

Bryon, K., Everaert, P., Lauwers, L., \& Van Meense, J. (2008). Time-driven activity-based costing for supporting sustainability decisions in pig production. Corporate Responsibility Research Congress.

Cooper, R., \& Kaplan, R.S. (1988). Measure Costs Right: Make the Right Decisians. Harvard Business Review, September, 96-103.

Dalci, I., Tanis, V., \& Kosan, L. (2010). Customer profitability analysis with time-driven activity-based costing: a case study in a hotel. International Journal of Contemporary Hospitality Management, 22(5), 609-637. https://doi.org/10.1108/09596111011053774

Everaert, P., \& Bruggeman, W. (2007). Time-driven activity-based costing: exploring the underlying model. Journal of Cost Management, 21(2), 16-20.

Everaert, P., Bruggeman, W., \& De Creus, G. (2008). Sanac Inc.: From ABC to time-driven ABC (TDABC) - An instructional case. Journal of Accounting Education, 26, 118-154. https://doi.org/10.1016/j.jaccedu.2008.03.001

Everaert, P., Bruggeman, W., Sarens, G., Anderson, S. R., \& Levant, Y. (2008). Cost modeling in logistics using time-driven ABC: Experiences from a wholesaler. International Journal of Physical Distribution \& Logistics Management, 38(3), 172-191. https://doi.org/10.1108/09600030810866977 
Fernie, J., Freathy, P., \& Tan, E.-L. (2001). Logistics Costing Techniques and Their Application to a Singaporean Wholesaler. International Journal of Logistics: Research and Applications, 4(1), 117-131. https://doi.org/10.1080/13675560110038103

Gervais, M., Levant, Y., \& Ducrocq, C. (2010). Time-Driven Activity-Based Costing (TDABC): An Initial Appraisal through a Longitudinal Case Study. Journal of Applied Management Accounting Research, 8(2), 1-20.

Goldsby, T.J., \& Closs, D.J. (2000). Using activity-based costing to reengineer the reverse logistics channel. International Journal of Physical Distribution \& Logistics Management, 30(6), 500-514.

https://doi.org/10.1108/09600030010372621

Gunasekaran, A., \& Sarhadi, M. (1998). Implementation of activity-based costing in manufacturing. Intemational Journal of Production Economics, 56-57, 231-242. https://doi.org/10.1016/S0925-5273(97)00139-4

Hedman, R., Sundkvist, R., Almström, P., \& Kinnander, A. (2013). Object-oriented Modeling of Manufacturing Resources Using Work Study Inputs. In Forty Sixth CIRP Conference on Manufacturing Systems (443-448). Elsevier B.V. https://doi.org/10.1016/j.procir.2013.06.013

Homburg, C. (2005). Using relative profits as an alternative to activity-based costing. International Journal of Production Economics, 95, 387-397. https://doi.org/10.1016/j.ijpe.2004.02.002

Hoozée, S., \& Bruggeman, W. (2010). Identifying operational improvements during the design process of a time-driven $\mathrm{ABC}$ system: The role of collective worker participation and leadership style. Management Accounting Research, 21, 185-198. https://doi.org/10.1016/j.mar.2010.01.003

Huang, S., Chen, H., Chiu, A., \& Chen, C. (2014). The application of the theory of constraints and activity-based costing to business excellence: the case of automotive electronics manufacture firms. Total Quality Management \& Business Excellence, 25(5), 532-545. https://doi.org/10.1080/14783363.2013.820023

Johnson, H.T., \& Kaplan, R.S. (1993). Contabilidade gerencial: a restauração da relevância da contabilidade nas empresas. Rio de Janero: Campus, Ed.

Kaplan, R.S., \& Anderson, S.R. (2004). Time-driven activity-based costing. Harvard Business Review, 131-138. http://www.ncbi.nlm.nih.gov/pubmed/15559451

Kaplan, R.S., \& Anderson, S.R. (2007). Time-Driven Activity-Based Costing: A Simpler and More Powerful Path to Higher Profits. Harvard Business School Press.

Kont, K., \& Jantson, S. (2011). Activity-Based Costing (ABC) and Time-Driven Activity-Based Costing (TDABC): Applicable Methods for University Libraries? Evidence Based Livrary and Information Practice, 6(4), 107-119. https://doi.org/10.18438/B8GG8Z 
Manunen, O. (2000). An Activity-Based Costing Model for Logistics Operations of Manufacturers and Wholesalers. International Journal of Logistics, 3(1), 53-65. https://doi.org/10.1080/13675560050006673

Ness, J., \& Cucuzza, T.G. (1995). Tapping the full potential of ABC. Harvard Business Review, 95, 130-138.

Pernot, E., Roodhooft, F., \& Van den Abbeele, A. (2007). Time-Driven Activity-Based Costing for Inter-Library Services: A Case Study in a University. The Journal of Academic Librarianship, 33(5), 551-560. https://doi.org/10.1016/j.acalib.2007.06.001

Sarokolaei, M.A., Saviz, M., Moradloo, M.F., \& Dahaj, N.S. (2013). Time Driven Activity based Costing by Using Fuzzy Logics. 2nd International Conference on Leadership, Technology and Innovation Management F, 75, 338-345. https://doi.org/10.1016/j.sbspro.2013.04.038

Saunders, M., Philip, L., \& Thornhill, A. (2009). Research methods for business students (5th ed.). Harlow: Pearson Education Limited.

Stouthuysen, K., Swiggers, M., Reheul, A., \& Roodhooft, F. (2010). Time-driven activity-based costing for a library acquisition process: A case study in a Belgian University. Library Collections, Acquisitions, and Technical Services, 34, 83-91. https://doi.org/10.1016/j.lcats.2010.05.003

Themido, I., Arantes, A., Fernandes, C., \& Guedes, A.P. (2000). Logistic costs case study—an ABC approach. The Journal of the Operational Research Society, 51(10), 1148-1157. https://doi.org/10.2307/253927

Varila, M., Seppänen, M., \& Suomala, P. (2007). Detailed cost modelling: a case study in warehouse logistics. International Journal of Physical Distribution \& Logistics Management, 37(3), 184-200. https://doi.org/10.1108/09600030710742416

Yin, R. (1994). Case Study Research: Design and Methods. SAGE Publications Ltd.

Yin, R. (2014). Case Study Research Design and Methods (5ª). SAGE Publications Ltd.

Journal of Industrial Engineering and Management, 2016 (www.jiem.org)

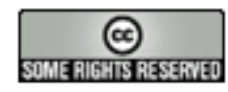

Article's contents are provided on an Attribution-Non Commercial 3.0 Creative commons license. Readers are allowed to copy, distribute and communicate article's contents, provided the author's and Journal of Industrial Engineering and Management's names are included. It must not be used for commercial purposes. To see the complete license contents, please visit http://creativecommons.org/licenses/by-nc/3.0/. 